RÉPLICA

\title{
DERECHA Y COMPRENSIÓN POLÍTICA. RESPUESTA A JOAQUÍN FERMANDOIS, RENATO CRISTI Y MAX COLODRO*
}

\author{
Hugo Eduardo Herrera \\ Universidad Diego Portales
}

\section{RECAPITULACIÓN INTRODUCTORIA}

\begin{abstract}
$E$ primer semestre de 2014 publiqué un artículo en Estudios Públicos sobre el llamado cambio de ciclo político y la derecha chilena. ${ }^{1} \mathrm{Al}$ preparar el artículo me percaté de que la complejidad del asunto abordado haría imposible terminar bien si no suspendía la redacción en cierto punto. Entonces decidí preparar un ensayo más extenso, que apareció en forma de libro, titulado La derecha en la Crisis del Bicentenario. ${ }^{2}$ Entre los comentarios que han realizado del libro y del artículo
\end{abstract}

Hugo Eduardo Herrera. Doctor en filosofía en la Julius-Maximilians-Universität de Würzburg. Profesor titular del Instituto de Humanidades, Universidad Diego Portales. Autor, entre otros, de Más allá del cientificismo, Carl Schmitt als politischer Philosoph y Sein und Staat. Email: hugoeduardoherrera@gmail.com.

* Respuesta de Herrera a las reseñas que Joaquín Fermandois y Max Colodro hicieron a su libro La derecha en la Crisis del Bicentenario (Santiago: Ediciones UDP, 2014), así como al comentario realizado por Renato Cristi sobre su artículo "La derecha ante el cambio de ciclo" (Estudios Públicos 135, 2014). Estos tres textos fueron publicados en Estudios Públicos 138 (2015).

1 "La derecha ante el cambio de ciclo", Estudios Públicos 135 (2014), 175202 (en adelante: DCC).

${ }^{2}$ Santiago: Ediciones UDP, 2014 (en adelante: DCB). 
académicos y personas vinculadas a centros de pensamiento, ${ }^{3}$ destacan tres trabajos aparecidos en el último número de Estudios Públicos, cuyos autores reaccionan a algunos de los planteamientos contenidos en ambos textos, pero además agregan sugerencias para la superación de la crisis de la derecha. El interés de los comentarios es, así, doble. Me ha parecido pertinente volver sobre ellos y discutir algunas de sus afirmaciones. De ese intercambio, entiendo, puede ganarse alguna claridad respecto de la situación ideológica de la derecha chilena y de la actividad de comprensión política que se le exige.

\section{LA CRISIS INTELECTUAL DE LA DERECHA}

Mi diagnóstico es que la derecha se encuentra en una crisis intelectual, la que caracterizo como la ausencia allí de un pensamiento político apto para contribuir a realizar una comprensión iluminadora de la situación actual. Esa crisis se expresa en la ausencia de la derecha en los grandes debates políticos, en los foros libres, en las organizaciones sociales; también en la incapacidad de incorporar las políticas públicas que asume dentro de un discurso sofisticado en un grado que las dote de justificación suficiente.

Si bien ya durante el gobierno de Sebastián Piñera se hablaba de "falta de relato", la indicación genérica carecía todavía de precisión. En este sentido, en el libro y el artículo me detengo, justamente, en analizar el fenómeno, intentando determinar con alguna exactitud el nivel en el que opera: se trata de un problema, en definitiva, de comprensión política. No parece existir un pensamiento lo suficientemente diferenciado en la derecha como para elucidar e interpretar la situación del país y ofrecerle salida, mostrando caminos de sentido. Además de un análisis de la

${ }^{3}$ Además de las columnas de Joaquín Fermandois, Pablo Ortúzar, Axel Kaiser, José Francisco García y Juan Luis Ossa, incluidas en un reportaje más extenso en Artes y Letras de El Mercurio (12/4/2015), ver Juan Ignacio Brito, "Oportuno y necesario", La Tercera (12/2/2015); Manfred Svensson, "Pluralismo en la derecha", ChileB (4/3/2015); Joaquín Castillo, "La derecha contra sí misma", Pulso (9/3/2015); Francisco Javier Valdés, "Haz todo, haz nada: 'La derecha en la Crisis del Bicentenario", El Mostrador (9/3/2015); Rafael Simian, "Herrera y 'La derecha en la Crisis del Bicentenario", El Mostrador (11/3/2015); Cristóbal Bellolio, "Un manual para salir del pozo", Capital (20/3/2015); Diego Schalper, "La pataleta intelectual de Herrera", El Mostrador (8/4/2015); Valentina Verbal, "La crisis de la derecha según Hugo Herrera", El Dínamo (13/4/2015). 
estructura de la comprensión política y de cómo el pensamiento político es requerido por ella, en el libro expongo las que podrían ser las bases para un tal pensamiento de derecha, apto para llevar a cabo la mentada comprensión política de la situación.

La actual crisis de la derecha tiene lugar en un contexto de cambio. La situación se está alterando. En el país se observan desplazamientos o modificaciones más bien fundamentales, los cuales tienen influencia innegable en la vida política y el debate público chileno. He destacado la acentuación del centralismo, la oligopolización y la disminución de la eficiencia agregada en la economía, la pérdida de legitimidad de la clase política, la atenuación del miedo, la flexibilización relativa de los ejes políticos del pasado reciente, una mayor distribución del poder del conocimiento, un empobrecimiento espiritual en grupos sociales importantes. ${ }^{4}$ Agregaría separadamente ahora: la irrupción de una clase media que pasó de ser alrededor de un veinte por ciento en 1990 a acercarse hoy a la mitad de la población. ${ }^{5}$ Estas alteraciones diferencian la situación actual respecto de la dictadura y la transición, y someten a la institucionalidad a presiones importantes, reveladas en la reactivación de los movimientos sociales, la polarización del debate y estudios de opinión que apuntan a un distanciamiento entre el pueblo y esa institucionalidad.

En este nuevo contexto en el que se encuentra el país, la derecha no ha logrado articular una comprensión política pertinente. Ella cuenta con profesionales y técnicos competentes, también con un acervo destacable de conocimientos económicos, pero carece, en cambio, de un pensamiento específicamente político, que la deje en posición de hacer una interpretación adecuada y más completa de la situación, y dotar sus opiniones de justificaciones suficientes. Entonces realiza una combinación que termina volviéndola poco eficaz en la discusión nacional. De un lado, tiende al puntillismo ejecutivo (cuando ha sido gobierno) y la escaramuza parlamentaria. Del otro, cuando la carga teórica del debate aumenta, ella suple la ausencia de un discurso político complejo o bien

\footnotetext{
${ }^{4}$ Para más detalle, DCB, cap. 1.

${ }^{5}$ En 2009 la clase media era más del 42 por ciento de la población en Chile; ver Francisco H. G. Ferreira, Julián Messina, Jamele Rigolini, Luis López-Calva, María Lugo y Renos Vakis, La movilidad económica y el crecimiento de la clase media en América Latina (Washington DC: Banco Mundial, 2012), 148.
} 
con simples alusiones a vagos ideales ("la libertad", se dice, por ejemplo, y la libertad da casi para todo), o bien repite ideas que, nacidas en plena Guerra Fría, vuelven difícil para la derecha hacer una elucidación diferenciada y orientadora de la situación, toda vez que el contexto es fundamentalmente distinto.

\section{COMPRENDER POLÍTICAMENTE}

El problema ante el que se encuentra la derecha, en último término, es de carácter hermenéutico. Éste puede ser descrito como sigue: la carencia de un discurso sofisticado y atingente ha determinado que ese sector haya devenido incapaz de desarrollar una comprensión específicamente política del tiempo presente.

Toda comprensión política está afectada por una tensión fundamental entre dos aspectos irreductiblemente involucrados en su actividad. La comprensión abarca una situación que es infinitamente singular, irrepetible, compleja. Esa comprensión se realiza, empero, de acuerdo a unas reglas y conceptos generales - un discurso-, a partir de los cuales se pretende hacer luz en el caso o situación y organizarlo en una totalidad de sentido. La generalidad de la regla se encuentra siempre en tensión con la particularidad y singularidad del caso.

La comprensión política exige atender tanto a la situación cuanto a las ideas. Esta tensión entre el caso y la regla hace que la comprensión política se mueva entre dos polos o extremos y un "aristotélico" medio virtuoso. En un extremo cabe hablar de una reducción mecánica de la singularidad y diversidad de la situación, de la peculiaridad del caso, según unas reglas preconcebidas. El exceso de abstracción, la inclinación descuidada hacia las ideas, que soslaya la atención a las circunstancias, importa el riesgo de subsumir la complejidad de lo real bajo un discurso que termina desconociéndola. En esta reducción se trata injusta, inadecuada, incluso violentamente a la peculiaridad de la situación y a los individuos que se ubican en ella. En tal extremo cae el político excesivamente ideologizado, que aplica su programa sin atender suficientemente a las particularidades del caso y los seres humanos que serán afectados por su decisión. El otro extremo es el de la contemplación puramente pasiva, estética, que se obnubila extasiada ante la infinitud insondable de lo real. La situación se divisa tan compleja o inabarcable, 
que no se sabe qué hacer con ella, cómo llevarla a una comprensión capaz de decir algo con sentido a su respecto y orientarla. En este segundo extremo cae el político que, agobiado por las incalculables consecuencias de su decisión, no se atreve a adoptarla y permanece taciturno, paralizado frente a la inabordable existencia.

La comprensión propiamente política se halla entre ambos extremos. Se le demanda adoptar una decisión, es decir, que en un momento determinado se suspenda la contemplación y la deliberación y se escoja una de las posibilidades de acción a la vista. Y se encuentra, además, siempre bajo el reclamo de la justicia, de tratar el caso de manera adecuada, proporcionada, no reduccionista. Vale decir, se requiere no sólo una teoría que elucide la situación, de tal suerte que en ella se logre orientación, sino que también una especial apertura a la realidad, una cercanía con ella, a partir de la cual se alcanza a saber de lo que allí efectivamente se trata.

Lograr una comprensión que sea, a la vez, capaz de decisión y abierta a la diversidad de la realidad es un desafío al que están persistentemente sometidas las élites intelectuales y políticas, bajo la premisa de que la prosperidad y supervivencia de las democracias republicanas penden de la capacidad de sus conductores de articular efectivamente la insondable y diversa voluntad popular en una decisión fundada en relatos suficientemente complejos. De la capacidad de orientar realmente la voluntad del pueblo según comprensiones plenas de sentido depende la legitimidad de aquéllas. ${ }^{6}$

\section{BASES PARA UNA EVENTUAL SALIDA}

En La derecha en la Crisis del Bicentenario (DCB), junto con plantear el problema de que la derecha carece de un pensamiento político lo suficientemente denso y sofisticado como para realizar una comprensión de la situación presente, intento mostrar los principios de un camino de salida. Para tal efecto, acudo a la historia y a autores de la derecha chilena. Es un camino que, como indico, debe ser complementado con la reflexión y la crítica, y el recurso a otras fuentes, incluidos los clásicos del pensamiento político. Reparo, además, en la necesidad de desplegar una

\footnotetext{
${ }^{6}$ Todo esto se encuentra más desarrollado en DCB, especialmente 49-76.
} 
atención mayor que la evidenciada por la derecha actual a la situación nacional y sus múltiples circunstancias.

Advirtiendo que resulta muy difícil, si no imposible, definir algo así como una "esencia" de la derecha, debido especialmente al dinamismo y la polisemia de los conceptos "derecha" e "izquierda", propongo una caracterización de la derecha chilena a partir de sus tradiciones intelectuales. Ellas le dan entidad y arraigo, así como una base intelectual más compleja que lo que exhibe el pasado más reciente. Identifico cuatro tradiciones: un pensamiento cristiano y liberal, uno cristiano social, otro nacional-popular y uno liberal y laico. Para los cuatro menciono autores y casos políticos. Propongo acudir a esas tradiciones y revitalizarlas críticamente, como manera de recomponer un pensamiento a la altura del tiempo presente y estimular una discusión que resulta necesaria para articular una comprensión política pertinente. Indico, en fin, algunos resultados que cabría esperar de la reconstitución del tejido intelectual y la renovación de la actividad comprensiva en la derecha (DCB, 125-132).

Algunos aspectos de ese esfuerzo — de crítica y propuesta - son abordados en los comentarios al libro y al artículo que le dio origen, que han publicado los profesores Fermandois, Colodro y Cristi en el número 138 de Estudios Públicos. En los tres, como he dicho, se contienen propuestas interesantes que apuntan a complementar el diagnóstico y el camino de salida que he planteado. Renato Cristi aboga por vincular a la derecha con el ideario del republicanismo. Max Colodro indica que una renovación de la derecha sólo será posible si ella se involucra en un nuevo tipo de praxis. Y Joaquín Fermandois recapitula su definición - lo digo preliminarmente: conservadora- de derecha y propone modos de acción en consecuencia. En el momento actual, cuando la derecha como sector político se ve enfrentada al desafío de actualizar su discurso, reflexionar sobre los tres artículos de marras puede ser relevante.

\section{JOAQUÍN FERMANDOIS: "INDIGENCIA DE IDEAS: LA DERECHA EN CHILE"}

En su comentario, Joaquín Fermandois, apoyándose en publicaciones suyas aparecidas entre los años 1995 y 2000, formula un criterio de distinción entre derecha e izquierda, así como una caracterización de aquélla, de la que cabe inferir modos de acción, lo que llama "una 
estrategia de ideas para la derecha". ${ }^{7}$ La propuesta es muy pertinente en varios de sus aspectos. Fermandois está atento a la experiencia y sus límites, a la relevancia de las espontaneidades sociales, al significado de los "cuerpos intermedios" para la libertad, al valor existencial del Estado (171-172).

Me parece, sin embargo, que, más allá de sus méritos específicos, hay un problema en la base sobre la cual la propuesta descansa. El entendimiento de la derecha que emerge del artículo de Fermandois es, a todas luces, mucho más sofisticado que el que usualmente se tiene de ella, pero acusa un énfasis que lo vuelve inadecuado. Puede llamárselo naturalizante.

La derecha surge en el texto comentado como una realidad "estructural", ella "nunca va a escapar de su origen" (169). Esa realidad está anclada en un dualismo antropológico (165-166 y el epígrafe de LeviStrauss, 149). Si la izquierda se vincula a una inclinación transformadora y crítica que emerge en torno al siglo XVIII, la derecha queda atada a una actitud que no renuncia a la razón y la crítica, pero es conservadora, asume que la realidad "tiene su razón de ser" (165).

La derecha, así fijada, posee "dos almas": una específicamente conservadora, otra liberal (170). La primera es "más escéptica acerca del constructivismo moderno, y más atenta al valor escondido de la herencia tradicional, aunque deba renovarse sin cesar" (170). La otra se liga "al concepto de libertad, aunque no se agota en él" (170). El liberalismo puede volverse intolerante respecto de los intolerantes, y alguna derecha liberal ha estado dispuesta a abandonar la libertad política en aras de la libertad económica (170-171). Lo que predomina, empero, es la unidad del fenómeno: "ninguna" de las almas "puede faltar por completo" (170). En tal caso, el fenómeno se pierde de vista, la derecha se disuelve.

Fermandois agrega que "no existe ni puede existir un cuerpo de ideas coherente que alimente a la derecha" (169). La realidad del sector es resistente al pensamiento. Cabe pensar, entonces, que si toda o parte de la derecha comienza a ser nutrida por conjuntos más o menos coherentes de ideas (la coherencia completa es siempre mera idea regulativa aquí), nuevamente la derecha se disuelve.

${ }^{7}$ Joaquín Fermandois, "Indigencia de ideas: La derecha en Chile", Estudios Públicos 138 (2015): 171. En adelante, se citará el artículo sólo con su número de página entre paréntesis. 
La operación de naturalización parece adquirir, por instantes, un tono marcadamente idiosincrático. Cuando Fermandois defiende ciertos modos de oligopolio (159), cuando llama a extremar el cuidado en el empleo del "concepto de oligarquía" ("se le debe tratar con pinzas", 158), cuando liga a la derecha con "los sectores más altos" (169), puede uno preguntarse si la naturalización no implica dejar atada excesivamente a la derecha a intereses económicos y de clase.

La inclinación naturalizante que se advierte en el artículo se enfrenta a dificultades teóricas y prácticas.

Aunque quepa admitir la influencia de aspectos antropológicos en su configuración, derecha e izquierda son conjuntos amplios de ideas, actitudes e intereses, de carácter fundamentalmente cultural, inmersos en procesos de discusión colectiva afectados por la historia, incluidas sus tradiciones, pero también su irreductible novedad, de tal suerte que la dinámica política puede ir adquiriendo direcciones imprevisibles. Esto no es algo que estén dispuestos a admitir usualmente los ciudadanos, mas es una circunstancia en la que el pensamiento político sí ha de reparar.

La descripción del surgimiento de la derecha que hace Fermandois pone a prueba su propia conceptualización. Quienes primero cuestionan las bases del orden tradicional son autores liberales, y el cuestionamiento coincide, para Fermandois, con "el nacimiento de la izquierda" (165). ¿Debemos, entonces, situar en la izquierda a quienes reivindicaron y reivindican los comienzos del proceso emancipatorio que dio origen al republicanismo moderno? Los excesos de constructivismo o pasivismo son, ciertamente, criticables en sí mismos, pero no facultan todavía para desconocer, por medio de definiciones, los respectivos vínculos de uno u otro tipo de pensamiento con un sector político. Hay quienes en la izquierda admiten que la realidad "tiene su razón de ser" (165), y hay en la derecha pesimistas que lo niegan. ¿Ha de sacárseles, respectivamente, de un lado y otro? Fermandois da a entender que sí. Cuando, por ejemplo, los liberales exploran su veta constructivista, ellos ya "no serían liberales de derecha" (172).

La afirmación de una distancia entre la derecha y un eventual "cuerpo de ideas coherente" que la nutra vale, quizás, para momentos determinados, pero no para la derecha pura y simple. Incluso si se descartan las inclinaciones constructivistas, y por coherencia se considera 
una exigencia razonable de sistematicidad, existen articulaciones teóricamente sofisticadas del liberalismo, o aun del pensamiento romántico, que permiten hablar de cuerpos de ideas coherentes a partir de los que la derecha se ha nutrido o puede nutrirse.

La conceptualización de la derecha y la izquierda que hace Fermandois es problemática en un sentido práctico. Al definir a la derecha de modo "estructural", al ligarla a actitudes fundadas antropológicamente, al vincularla a dos tendencias específicas que deben existir en ella, al distanciarla de conjuntos de ideas coherentes y relacionarla - aunque matizadamente, de todos modos- con intereses de clase, Fermandois limita, quizás demasiado severamente, las posibilidades de sumir a la derecha en procesos reflexivos de alcance. En su concepción, los aspectos heterónomos operan restringiendo el campo legítimo de la espontaneidad de tales procesos reflexivos. No cabe ya pensar, por ejemplo, en una derecha más crítica del statu quo que la propia izquierda, ni en una que soslaye el "alma" liberal o conservadora, ni que se tome en serio las tareas de desplegar un pensamiento político coherente en grados más altos que los de la yuxtaposición, ni que pretenda emanciparse, diferenciadamente pero con decisión, de ataduras de clase. Puesta, sin mayores clarificaciones, frente al momento actual, la conceptualización de Fermandois puede llegar a parecer difícilmente compatible con los intentos de reconstituir un pensamiento lo suficientemente complejo, desligado de atavismos e intereses adquiridos en un grado requerido como para darle a la derecha un talante y una visión específicamente políticos.

Creo que la consideración del problema habría ganado en pertinencia si Fermandois hubiese reparado en un asunto que abordo en el libro con bastante detención, que no le es completamente extraño, pero que en su comentario omite. Se trata, precisamente, del tema de la comprensión política (DCB, 12-16, 45-46, 49-56, 74-76, 125-132 y otras). Ésta es la cuestión central de mi libro, de eso se trata y, en este sentido, su omisión en su reseña es llamativa.

Dado su problema central, el libro no puede ser "de batalla", ni tratarse, "en lo básico, de lamentar la anomia intelectual de la clase política de derecha y su dificultad en expresar metas estratégicas e ideas iluminadoras y convincentes acerca de sus objetivos" $(151,153)$. Hay algo más: un planteamiento sobre las bases para una comprensión política de 
la situación. Este foco es el que explica la decisión de prestarle menor atención a la historia fáctica de la derecha (DCB, 117), tema interesante pero más propio de otro tipo de estudio. ${ }^{8}$

Es ese asunto central del ensayo el que me obliga a acudir a autores diversos, que no sólo comparten "temas comunes" (154), sino una hermenéutica filosófica y política en la que se repara, con detención y novedad, en el problema comprensivo. Considerarla, a ella y al fenómeno que estudia, termina resultando muy relevante. Ante una consciencia despierta respecto del proceso comprensivo y sus implicancias, se vuelve, justamente, cuestionable de forma severa la naturalización de la derecha y la izquierda. La comprensión siempre es de situaciones únicas y nuevas. Frente a esas situaciones, y como muestran plausiblemente Gadamer, Derrida o Schmitt, las ideas no permanecen inalterables, sino que modifican su sentido; han de modificarlo, si no se quiere caer en los excesos del reduccionismo ya comentado. ${ }^{9}$ Los sentimientos y posiciones de partida se incorporan también en el proceso y entonces puede ocurrir que un sector político cambie, incluso, en algunos aspectos, radicalmente, en la precisa medida en que su consciencia política se ve exigida por las diversas tomas de posición comprensiva ante las siempre nuevas circunstancias. Es lo que, de hecho, le está pasando a nuestra derecha, si se atiende a su actual ebullición (relativa, por cierto, y evidente con mayor fuerza en sectores más jóvenes que en la "vieja guardia", pero real): partidaria en su momento de una comprensión afín a la dictadura y a un economicismo neoliberal, hoy cae en la cuenta, crecientemente, de sus excesos y se percata de la inadecuación del discurso que ha portado y de algunos de los intereses y atavismos que encarna.

Esa atención del libro a lo que cabría llamar la hermenéutica política permite, creo, explicar la diferente aproximación que tenemos con Fermandois al asunto de la oligarquía. Hemos leído que él exige que se trate "con pinzas" el concepto (158), al que aludo — dice— "vagamen-

${ }^{8}$ Esta historia fáctica de la derecha incluye, como bien indica Fermandois, entre otros aspectos, el detalle de su "trayectoria electoral", la "fuerza o debilidad de la que ha gozado en el sistema político", la "base social de sus componentes" y "de su electorado" (153).

${ }^{9}$ Ver Carl Schmitt, Gesetz und Urteil (Múnich: Beck, 2009), 28, 32, 35; Jacques Derrida, "Force de loi: Le 'fondement mystique de l'autorité", Cardozo Law Review 11 (1990): 948, 960, 970; Hans-Georg Gadamer, Wahrheit und Methode, Gesammelte Werke vol. I (Tübingen: Mohr Siebeck, 1990), 313 ss. 
te" (159). En el libro me encargo de distinguir entre élite y oligarquía, según un criterio que no puedo sino tener siempre a la vista, a saber, el de la capacidad de comprensión política. La oligarquía no coincide simplemente con "los sectores altos" (169). Hay élite, hay oligarquía. La élite deviene oligárquica cuando pierde aptitud hermenéutica: cuando antepone "a los anhelos populares [...] los intereses de clase"; cuando "carece de la amplitud comprensiva suficiente como para incluir al país entero" (DCB, 27, 28). Aquí no estoy haciendo nada muy nuevo, sino empleando una caracterización usual en la filosofía y la teoría política desde Aristóteles. ${ }^{10}$

La tematización detenida de la cuestión de la comprensión política le hubiese probablemente exigido a Fermandois revisar su posición en lo que tiene de naturalizante, pues hay allí un criterio que permite colocar delante los intereses y sedimentaciones en su carácter de tales. La apertura a la situación, el esfuerzo por abarcarla, apropiándose, por cierto, de tradiciones de pensamiento y acción, pero realizando un ejercicio reflexivo y crítico, vinculado antes a los méritos de las justificaciones frente a contextos emergentes que a sedimentaciones y atavismos, es condición de un pensamiento político vivo, así como también de la espontaneidad mental que cabe exigir del mundo intelectual, y que lo vuelve, precisamente, capaz de fecundar la realidad. A algo así es a lo que Fermandois, por lo demás, parece aludir, cuando, en uno de los artículos suyos a los que remite en su reseña, indica: "habrá que señalar hacia un futuro cuyo sentido será elaborado a partir de herencias, pero cuya imagen final habrá que ir escogiendo en cada momento". ${ }^{11}$

\section{RENATO CRISTI: “¿UNA DERECHA REPUBLICANA?"}

Renato Cristi dirige su comentario al primer artículo que publiqué en Estudios Públicos ("La derecha ante el cambio de ciclo", DCC). Cristi considera el tema central de mi reflexión, a saber, la cuestión de la comprensión política y las carencias de la derecha en este asunto, ${ }^{12}$

\footnotetext{
${ }^{10}$ Ver Aristóteles, Política: III, 7, 1279 b 5-10 y IV, 5-8.

${ }^{11}$ Joaquín Fermandois, “¿Qué futuro tiene la díada derecha-izquierda?”, Estudios Públicos 60 (1995): 349-374.

12 Renato Cristi, “¿Una derecha republicana?”, Estudios Públicos 138 (2015): 217-18, de ahora en adelante citado sólo con número de página.
} 
aunque cuando aborda en particular a los autores a los que me refiero lo hace de un modo que los vuelve difícilmente aprovechables para una actividad de comprensión política renovada en la derecha. Ése es, principalmente, mi punto de diferencia con él. En la parte final de su artículo, y puestos a la tarea de renovar el pensamiento de la derecha chilena, propone conducirla "por la senda republicana" (229). Del republicanismo, la derecha podría obtener orientaciones valiosas: el reconocimiento de la participación popular "en el autogobierno de la polis como un fin intrínseco" (229); del estatuto y valor específico de los "bienes comunitarios" (230); de la importancia de la dimensión social y política de la vida y la relevancia política y autorrealizativa de la propiedad (231); una comprensión de la subsidiariedad como principio que apunta al "empoderamiento democrático de los individuos" (232); consciencia sobre la exigencia de "revertir la fractura social que trajo consigo el neoliberalismo" expresada de manera patente en la fragmentación de la ciudad (233).

La sección propositiva del artículo es relevante y asimilable, hasta cierto punto, por grupos importantes de la derecha más reflexiva. Sin embargo, respecto de su comentario a mi referencia a Encina, Edwards y Guzmán, me parece necesario hacer algunas observaciones. Probablemente parte de nuestro desacuerdo se disuelva si soy más explícito en indicar que mis referencias a ellos no apuntan a rehabilitar los personajes en general ni aspectos idiosincráticos de sus pensamientos. De hecho, y como el propio Cristi lee, entiendo, por ejemplo, que la doctrina de Jaime Guzmán está superada, hasta cierto punto, precisamente desde la perspectiva del mismo autor (223), pues — aunque en esto no vamos a estar de acuerdo- Guzmán fue, antes que un intelectual, un político, el cual — como Cristi tiene que admitir - cambiaba, incluso radicalmente, sus posiciones - agrego yo - según fuesen variando los contextos. Sólo entonces pueden explicarse las incongruencias en los escritos de Guzmán que Cristi detecta (221), donde abandona viejos discursos y se pliega a nuevos, va del "corporativismo" al neoliberalismo (219-220) y su pensamiento se altera "en sus líneas esenciales" (220 n. 2). Así, el carlista joven deviene demócrata liberal en el tiempo de Allende y luego adhiere, entusiasta, a la dictadura, para apoyar las reformas constitucionales en 1989 y presentarse, ese año, de candidato a las elecciones y votar por Gabriel Valdés - y no por el candidato de 
la derecha - para presidente del primer Senado. Nunca sabremos hacia dónde habría girado el inquieto político, pues fue asesinado recién a comienzos de la transición.

Lo que me interesa de Guzmán, para los efectos del artículo y luego del libro, antes que sus doctrinas — por lo demás, casi siempre de escaso nivel teórico y carentes de interés fuera de su contexto-, es su capacidad de comprensión política. Si el Guzmán ideólogo es poco relevante, el Guzmán político es de vuelo mayor. No me parece que sea mero oportunismo lo que explica sus giros, sino una combinación de aptitud prospectiva y una inquietud fundamental por resguardar la libertad del espíritu en medio de las dinámicas de poder seculares. Eso es casi lo único que Guzmán no cambia a lo largo de su periplo ideológico: su fe (y su miedo). ${ }^{13}$ El corporativista pensaba así, el defensor de la democracia liberal contra el marxismo, el partidario de Pinochet, el redactor de la Constitución y el senador por Santiago poniente.

Cristi sostiene que de Guzmán no se podría decir — como hagoque fue simplemente "un político inteligente, no un teórico". Ésta sería "la defensa suya que esgrimen sus partidarios en la UDI" (221). Lo que uno nota en la UDI, en cambio, es algo más parecido a lo de Cristi que a lo mío: una lectura que lo entiende precisamente como teórico, la mente tras doctrinas perennes. Entre representantes de ese partido leemos: "El modelo de Jaime Guzmán no sólo sirve aún, sino que es plenamente capaz de dar respuesta integral a los actuales $-\mathrm{y}$ permanentes- dilemas políticos". ${ }^{14}$ Coincidente con la gente de la UDI, Cristi considera que en Guzmán sí habría un "pensamiento político", fundado en "claves conceptuales rigurosamente definidas" (221), a saber: "una denuncia del estatismo, parte esencial de una estrategia que intenta desacreditar al Estado social redistributivo; una concepción de la propiedad como un derecho real (ius in rem) que pone en jaque su función social; afirmación del principio de subsidiariedad en desmedro del principio de solidaridad [...]; redefinición de la idea republicana del bien común

${ }^{13}$ No me parece posible atenuar este factor al punto en que lo hace Cristi. Ciertamente, la capacidad de influir en la disolución de la Dina evidencia un poder (222). Pero se trató, indudablemente, de una lucha de poderes, en la que le cabía a Guzmán temer por la propia integridad.

${ }^{14}$ Carlos Frontaura y Claudio Arqueros, "Pensamiento de Jaime Guzmán”, La Tercera (18/9/2012); ver Gonzalo Rojas, "No se juega con Guzmán”, en el portal viva-chile.cl, 9/2012. 
reduciéndolo, como enseña Hayek, a la suma de bienes individuales; $\mathrm{y}$, en último término, el reconocimiento de la prioridad ontológica y de finalidad de los individuos con respecto a la sociedad" (222). ${ }^{15}$

Esta lectura presenta problemas. Las variaciones o alteraciones de "líneas esenciales" que exhibe el pensamiento de Guzmán son tan relevantes - como el mismo Cristi se ve obligado a admitir (ver lo ya dicho sobre las incongruencias y cambios) - que hacen imposible hablar de uno y el mismo pensamiento. ¿Cuál sería ése? ¿El corporativismo? ¿La defensa de Guzmán de un sistema donde los trabajadores participen en el control y las utilidades de la empresa? ¿El liberalismo económico, al que se pliega "más tarde"?

El "pensamiento político" de Guzmán que describe Cristi es un amasijo de doctrinas heterogéneas entre sí. Él mismo tiene que reconocer inconsistencias, incluso dentro de un mismo texto. Por ejemplo, al cristianismo se añade una concepción presuntamente atomista del bien común. Entonces habría que mostrar cómo ideas tan distintas se dejan incorporar en una teoría "de claves conceptuales rigurosamente definidas". ¿Cabe seguir hablando de un "pensamiento político" o hay que reconocer, en cambio, que la yuxtaposición de doctrinas hábilmente asumidas y desechadas según las circunstancias y bajo el imperativo de la libertad del cristiano es lo que mejor caracteriza su actitud?

Cristi indica que yo hago una "defensa de Guzmán", pero que me daría cuenta de que ella es "debatible", por eso llegaría a "relativizar su legado intelectual y político", cuando digo que sus ideas, atingentes en la Guerra Fría, no lo son ya hoy si se aplican "sin mayores aclaraciones y matizaciones”. Como cavilando, se pregunta: “¿Qué sentido podría tener entonces la defensa que monta Herrera de su pensamiento y actividad política?" Y responde: "Posiblemente la intención de Herrera es

${ }^{15}$ En el texto de Cristi, Guzmán emerge como paradigma de anti-republicanismo (229). Debe matizarse la apreciación. Guzmán, como en muchas otras materias, también aquí cambió de posiciones. Si durante la UP admite, por ejemplo, la participación de los trabajadores en la conducción y utilidades de la empresa, y defiende la institucionalidad democrático-liberal, aquello cambia luego del Golpe. Entonces aparece nítidamente el anti-republicano. Un juicio justo respecto de la posición de Guzmán ha de reparar, empero, en las circunstancias extremas en las que se halla el país del Guzmán anti-republicano. Ni la "vía chilena al socialismo", ni luego el FPMR son contertulios republicanos. Nada de esto alcanza a justificar, sin embargo, la actitud de Guzmán en materia de derechos humanos. 
proteger lo esencial de su pensamiento" (223). Esta última afirmación es evidentemente incorrecta, pues ya he dicho que no existe algo así como "lo esencial" de su "pensamiento", toda vez que no existe "el" pensamiento de Guzmán como conjunto coherente de doctrinas. Lo que defiendo, entonces, no es el "pensamiento" de Guzmán, sino su actitud de apertura comprensiva y adaptación a las circunstancias diversas para proteger lo que consideraba fundamental: la libertad del espíritu. Sólo si Cristi me atribuye una lectura de Guzmán similar a la de él (antes como teórico que como - mero- político), tiene sentido su sorpresa ante lo que en verdad no debiera generarla: el reconocimiento de la actitud de quien cambia doctrinas según las circunstancias.

Aunque no me resulta posible dejar de valorar la contribución de Guzmán a la desaparición de la Dina, la crítica de Cristi al efectivo compromiso de él con el dolor de las víctimas de la dictadura me lleva a acercarme a esta parte de su lectura, por la siguiente razón: existen testimonios de que Guzmán ayudó a algunas víctimas de violaciones a los derechos humanos. Esa ayuda supone que sabía a ciencia cierta lo que estaba ocurriendo en las mazmorras del régimen. Ahora bien, si lo supo, ¿por qué no realizó una condena no sólo explícita, sino más persistente y enfática de tales sucesos? ¿Habrá pensado, cual Tomás Moro, que era legítimo y practicable intentar conducir a la dictadura hacia cursos menos turbios desde su interior? ¿Puede, el agudo político, no haber advertido las dimensiones de lo que estaba ocurriendo y las dificultades de alterarlo? Estas interrogantes vienen a relativizar, por cierto, la tesis sobre la capacidad prospectiva de Guzmán.

Respecto de los comentarios de Cristi sobre mis referencias a Francisco Antonio Encina y Alberto Edwards, he de insistir en que tampoco me interesan esos autores pura y simplemente, en bloque, sino que los traje a colación para un fin determinado, que queda, por lo demás, bastante explícito tanto en el artículo como en el libro. Las referencias que hago a ellos no consideran sus acciones políticas en general, ni siquiera su pensamiento en forma global, menos aún sus peculiaridades idiosincráticas. Cristi mismo se percata de esto, en el caso de Encina (225). Creo que tanto éste como Edwards exhiben una capacidad destacable de combinar la penetración prospectiva en la situación concreta con ideas que permiten comprenderla iluminadoramente. Cristi, además de insistir, una vez más, en el autoritarismo de ambos, espeta que en ellos "la influencia de autores y circunstancias foráneas es tan marcada que 
interfiere con lo que podría ser una 'mirada cara a cara' de la realidad concreta" (228). Sin embargo, "por sus frutos los conoceréis", y esto es lo que considero valioso específicamente en mi reflexión: la identificación de lo que cabe designar la "mecánica" tras un proceso de desajuste político y el diagnóstico de la llamada "Crisis del Centenario" (expresada como "un malestar confuso y generalizado", que da cuenta de "una especie de desequilibrio agudo entre las necesidades y los medios de satisfacerlas") ${ }^{16}$, la consciencia respecto de los resortes sobre los que se asienta un régimen estable (no sólo lazos materiales, sino que también espirituales; una adecuación de la institucionalidad a las pulsiones y anhelos populares), la lucidez metodológica sobre los aspectos a tener en cuenta en una interpretación pertinente de la realidad (ver las referencias en DCC, 198), la participación de Encina en el debate educacional y su idea de la enseñanza como procedimiento y mediadora para dar cauce a inclinaciones populares hondas. Todas éstas son expresiones perennes de capacidad de comprensión política —omitidas por Cristi-, de las cuales la derecha actual, ensimismada en sus remedos de abstracciones de Guerra Fría, tendría mucho que aprender. Pero no sólo ella. Todos los sectores dirigentes en una "democracia republicana" (229) necesitan mantenerse atentos a las exigencias de la comprensión política, si quieren lograr sobreponerse a las mutaciones y demandas de contextos desafiantes y eventualmente conflictivos.

\section{MAX COLODRO: "DE LA CRISIS AL FUTURO"}

En su comentario, Max Colodro reconstruye sucinta y pertinentemente las diversas partes de mi libro, complementando su tesis central con una propuesta parcialmente distinta. ${ }^{17} \mathrm{Da}$ Colodro con lo que llamaría el tema fundamental del texto, a saber, la cuestión de la comprensión política (178-179). Concuerda, asimismo, en parte, con el diagnóstico: habría un "desfase entre acción y discurso", el cual, nos dice, "tiene a la derecha viviendo una severa crisis de posicionamiento y credibilidad" (185). Sin embargo, tanto o incluso más importante que

${ }^{16}$ Francisco Antonio Encina, Nuestra inferioridad económica (Santiago: Universitaria, 1955), 177.

17 Max Colodro, "De la crisis al futuro", Estudios Públicos 138 (2015), de aquí en adelante citado sólo con su número de página. 
esta debilidad en el pensamiento de la derecha, lo sería una debilidad que Colodro sitúa en un nivel "más profundo", y que tiene que ver con la actitud de la derecha, con su ethos, uno "que desde hace bastante tiempo ha impedido generar una mirada integral e integradora del conjunto de la nación" (185).

Esa actitud carga consigo y está afectada fundamentalmente por tres lastres. Porta la derecha un "complejo ético que se arrastra desde el régimen militar y que, por falta de una adecuada y profunda autocrítica respecto de su responsabilidad en las violaciones a los derechos humanos, hoy tiende a inhibir las convicciones con que la derecha hace sus planteamientos" (179-180). Además, en el sector existe una "resistencia cultural al cambio" y "atavismos de clase de su élite dirigente". Todos ellos terminan limitando "severamente sus posibilidades de conexión con un mundo social más complejo y diverso" (180). Vale decir, el problema de la derecha, a juicio de Colodro, no es propiamente intelectual, podría decirse, sino moral.

De allí se sigue que el remedio a la crisis no tenga que ir por la vía del pensamiento, sino de la acción: la derecha ha de lograr "instalarse en 'un hacer' nuevo e inédito, que le permita adentrarse en otras realidades socioculturales del mundo contemporáneo" (187). Como se trata de instalarse en un hacer abierto al futuro, no tiene demasiada importancia "ir al pasado a rescatar tradiciones de pensamiento" (187). "Conocer y reconocer" la realidad política y social "no es contemplarla desde la distancia, al abrigo de tradiciones intelectuales o ideológicas; implica, simplemente, vivirla, ser parte de ella y de los desafíos individuales y colectivos que ésta supone" (188). Colodro complementa, pero también parece invertir mi propuesta. En el principio no es el Verbo, sino la acción. "La renovación de las ideas será —al final y más bien- el resultado de estas prácticas y no su principio; el fruto de un modo de conectarse con formas de vida y sentidos comunes inéditos, desde donde las ideas podrán reelaborarse en su dimensión propiamente política" (188).

Ciertamente Colodro tiene razón, cuando destaca la relevancia que en todo proceso de comprensión política posee la atención a la situación concreta. Cita un pasaje en el cual considero dicha atención (188). Concuerdo con él cuando indica que el cambio que requiere la derecha no es puramente discursivo. Sin embargo, me atrevería a indicar que él 
establece una división por momentos excesiva entre el campo teórico y el práctico. La comprensión política es también un trabajo intelectual, aunque, como digo, no se trata de una labor desarraigada o puramente especulativa, sino, ante todo, de hacer luz y orientar prácticamente una situación cargada de sentido. O sea, teoría y praxis están inescindiblemente unidas. No hay, por lo mismo, una disyuntiva entre pasado y futuro. Se trata de ajustar una situación presente, elucidándola también con la ayuda de tradiciones de pensamiento, pero de tal suerte que no resulte mecánicamente subsumida, sino que se considere su novedad irreductible, su singularidad, su carácter único, y se le dé una orientación desplegante. Vale decir, la observación de Colodro es correcta, siempre y cuando no se entienda a la acción o la praxis aisladamente. Sin el apoyo del pensamiento político, la acción termina en el activismo. Lamentablemente, nuestra derecha, campeona de las políticas públicas pero muchas veces indiferente - cuando no hostil— respecto del pensamiento más sofisticado, acaba a menudo cayendo en ese extremo.

Algo parecido puede decirse de la indicación de Colodro relativa a que el problema de la derecha es más bien ético que intelectual. La falta de autocrítica o la insensibilidad en ella respecto de la dictadura, sus atavismos de clase, su desconfianza hacia el futuro son - como destaca - también cuestiones de actitud o éticas. Pero se trata de posiciones cuya conservación se vuelve quizás facilitada, precisamente, debido a la falta de reflexión sobre sus alcances, proceso en el cual el pensamiento político es fundamental. Además, ha de considerarse que una parte importante de lo que resulta criticable en la actitud ética de la derecha tiene que ver no con males espontáneos, sino con defectos en cuya aparición también influyeron elaboraciones doctrinarias. Elaboraciones poco sofisticadas, por cierto, pero que se expresan en dispositivos e instituciones, y en series de creencias más o menos coherentes que articulan a una parte hasta ahora dominante del sector. La superación de aquellos lastres actitudinales sólo puede realizarse si, junto a un acercamiento a la realidad, se lleva a cabo, y desde el inicio, una reflexión ilustrada por el pensamiento político acerca de las construcciones mentales que los facilitaron. 


\section{A MODO DE CONCLUSIÓN: SOBRE LA COMPRENSIÓN}

Las observaciones de los tres autores que estoy comentando me permiten volver sobre el problema de la comprensión política y perfilarlo de mejor manera. Esto, que he tratado de hacer en cada caso, lo planteo ahora conjuntamente, para concluir.

Ante una situación radicalmente distinta a la de la Guerra Fría, la derecha se halla frente a un desafío intelectual mayor: articular un pensamiento político lo suficientemente complejo como para comprender de manera adecuada esa situación y ofrecer caminos plenos de sentido. Dicha comprensión también pone al sector bajo la exigencia de compenetrarse con la situación, atender cuidadosamente a ella, auscultarla prospectivamente. Entonces será posible, para la derecha, una comprensión política como algo distinto a una subsunción mecánica de la realidad bajo ideas impertinentes o la aproximación fragmentaria a tal realidad según una amalgama de retazos de discursos, políticas públicas y marketing. Tal comprensión, no obstante que requiere del pensamiento, es siempre de carácter teórico y práctico: ilumina una situación política para abrirle caminos de sentido por medio de decisiones. Ella es un momento imprescindible en el camino de liberación de intereses de clase y atavismos que ha de recorrer la derecha para acentuar su talante de sector eminentemente político. La exigible nueva comprensión se enfrentará, precisamente, a los atavismos e intereses señalados. Su fecundidad dependerá de la fidelidad de quienes la realicen - investigadores, pero fundamentalmente políticos - antes que a tales atavismos e intereses, a los resultados de la consideración racional y la crítica, lo mismo que de la apertura atenta a la realidad. Las naturalizaciones, como las que, me parece, se advierten en el artículo de Fermandois, conspiran aquí contra un esfuerzo auténtico de renovación y dejan sus observaciones, la mayor parte de las veces elogiables, puestas sobre una base que las hace perder potencial para una reflexión que no se conforme excesivamente con el statu quo. Todo esto no quiere decir que la comprensión política que ha de realizar la derecha tenga que desplegarse en una especie de vacío. Ya lo he dicho: no se trata de una especulación puramente teórica y desarraigada, sino de entender la situación nacional a partir de un pensamiento político, sin subsumirla ni abandonarla. Es menester atender a la realidad. En este sentido, el pensamiento político chileno, no obstante que usualmente menos denso filosóficamente que el de los 
clásicos políticos universales, tiene la ventaja de guardar mayor cercanía respecto de la situación. Las obras de Encina, Galdames, Góngora o Edwards son ciertamente de menor enjundia teórica que las de Hegel, Kant, Hobbes o Montesquieu. Cabe criticar muchos aspectos en aquéllas que son, además, difícilmente compatibles con un republicanismo como aquél por el que aboga Renato Cristi. Pero, a diferencia de las obras de los clásicos de otras latitudes, las de nuestros autores son escritas, como decía Nicolás Palacios, por chilenos y "para los chilenos". A objeto de lograr apreciar el potencial comprensivo de estos autores, me atrevería a recomendar un principio hermenéutico muy fructífero, que por lo demás solemos aplicárselo también a los clásicos (de lo contrario, los textos del Estagirita, por ejemplo, o incluso pasajes de otros autores más cercanos, nos aparecerían como aglomeraciones extrañas de saberes vetustos o afirmaciones inadmisibles para nuestras depuradas consciencias): separar —y esforzarnos por separar — lo idiosincrático de aquello que aún puede servirnos.

Hay un momento en el que el uso de la razón logra conectar con pensamientos iluminadores y descubrir, incluso respecto de la praxis. Entonces, en el descubrimiento que orienta, coincide la plenitud sabida con el abandono de lo que era sólo prejuicio o simple ideación constructiva. EP 